Check for updates

Cite this: RSC Adv., 2019, 9, 10569

Received 24th February 2019

Accepted 28th March 2019

DOI: $10.1039 / c 9 r a 01411$ j

rsc.li/rsc-advances

\section{Efficient catalytic conversion of corn stalk and xylose into furfural over sulfonated graphene in $\gamma$ - valerolactone $\uparrow$}

\author{
Jianru Ma, ab Wenzhi Li, (D) *a Shengnan Guan, ${ }^{a}$ Qiying Liu, (D) ${ }^{\mathrm{b}}$ Qingqing Li, (D) ${ }^{\mathrm{b}}$ \\ Chaofeng Zhu, ${ }^{a}$ Tao Yang, ${ }^{a}$ Ajibola Temitope Ogunbiyi ${ }^{\mathrm{a}}$ and Longlong Ma*b
}

\begin{abstract}
Sulfonated graphene (SG) was prepared and employed to convert corn stalk and xylose into furfural. Transmission electron microscopy (TEM), scanning electron microscopy (SEM), X-ray photoelectron spectroscopy (XPS) and Fourier transform infrared spectroscopy (FT-IR) were used to characterize SG. The effects of reaction time, temperature, substrate loading, catalyst dosage and solvents on the reaction were researched and optimized. SG exhibited high catalytic activity in the conversion of xylose and corn stalk to furfural. A fairly high furfural yield of $96 \%$ was achieved at $150{ }^{\circ} \mathrm{C}$ from xylose and a $71.9 \%$ furfural yield was obtained when using a 10.7 ratio (mass ratio: xylose to SG) at $140{ }^{\circ} \mathrm{C}$. While a $48 \%$ furfural yield was obtained from corn stalk (based on the starting combined moles of xylan and glucan in corn stalk; yield was $>100 \%$, if based on only xylan) using a substrate loading (corn stalk to catalyst mass ratio) of 2.14 and a 19\% 5-hydroxymethylfurfural (5-HMF) yield was obtained. What's more, a $43.9 \%$ yield of furfural was obtained in only $20 \mathrm{~min}$. In addition, the reusability of SG was also investigated and shown to have good stability for xylose dehydration.
\end{abstract}

\section{Introduction}

In recent years and with the rapid development of the world's economy, the consumption of fossil based resources has been excessively increasing, which has contributed to serious environment pollution and global warming. Consequently, renewable resources, one of which is biomass, have attracted great attention as promising candidates for producing high valueadded chemicals and biofuels ${ }^{1}$ with minimal adverse environment effects. Studies have shown that more than 300 kinds of chemicals can be used as raw materials for the production of chemical products, and some of them are considered as promising biochemical substances by the US Department of Energy and other scholars, such as furfural, 5-hydroxymethylfurfural (5-HMF), levulinic acid, etc. ${ }^{2}$ Furfural is mainly derived from hemicelluloses and can be used to produce many useful chemicals, such as furfural alcohol, ${ }^{3-5}$ tetrahydrofurfuryl alcohol, ${ }^{6,7} \gamma$-valerolactone $(\mathrm{GVL})^{8,9}$ and 2-methylfuran, tetrahydrofuran. ${ }^{\mathbf{1 0 , 1 1}}$

${ }^{a}$ Laboratory of Basic Research in Biomass Conversion and Utilization, Department of Thermal Science and Energy Engineering, University of Science and Technology of China, Hefei 230026, PR China.E-mail: liwenzhi@ustc.edu.cn

${ }^{b}$ CAS Key Laboratory of Renewable Energy, Guangzhou Institute of Energy Conversion, Chinese Academy of Sciences, Guangzhou 510640, PR China. E-mail: mall@ms.giec. ac.cn

$\dagger$ Electronic supplementary information (ESI) available. See DOI: $10.1039 / \mathrm{c} 9 \mathrm{ra} 01411 \mathrm{j}$
Mineral acids $\left(\mathrm{H}_{2} \mathrm{SO}_{4}\right.$ or $\left.\mathrm{HCl}\right)$ are currently the important catalysts for commercial production of furfural. ${ }^{12,13}$ Recently, some efficient homogeneous catalysts were used for the dehydration of xylose to furfural in single-phase or biphasic system. $\mathrm{FeCl}_{3} \cdot 6 \mathrm{H}_{2} \mathrm{O}$ was used for the production of furfural from xylose in aqueous environment through hydrolysis to produce a strong acidic medium. ${ }^{14} \mathrm{CrCl}_{3}$ as a bifunctional catalyst, combined with ionic liquid, was found to produce furfural from xylan with a $63 \%$ yield with the aid of microwaves at $200{ }^{\circ} \mathrm{C} .{ }^{15} \mathrm{AlCl}_{3} \cdot 6 \mathrm{H}_{2} \mathrm{O}$ was used as catalyst to prepare furfural from xylose with a $75 \%$ furfural yield in a water-tetrahydrofuran biphasic medium. ${ }^{16}$ However, commercial production of furfural still faces greater challenges and difficulties, as this process comes with great issues such as environment pollution and equipment's erosive damage caused by homogeneous acid catalysts. ${ }^{17}$ Although the use of homogeneous catalysis is an efficient method to produce furfural, in order to recycle catalysts and avoid toxic homogenous acids and equipment corrosion problem, heterogeneous catalytic systems have been received greater attention, partly because it allows for the catalysts reusability. Solid acid catalysts have the most potential for furfural production. $\mathrm{SO}_{4}{ }^{2-} / \mathrm{ZrO}_{2}-\mathrm{Al}_{2} \mathrm{O}_{3} / \mathrm{SBA}-15$ solid acid catalyst was prepared for the dehydration of xylose in toluene-water biphasic system with a $53.4 \%$ furfural yield at $160{ }^{\circ} \mathrm{C} .{ }^{18}$ Dias et al. used sulfonic acid-anchored MCM-41 to produce furfural from Dxylose. ${ }^{19}$ Also, Gurbuz and co-workers studied various solid acid catalysts to convert hemicellulose into furfural. ${ }^{20}$

Among these heterogeneous catalysts, sulfonated carbonbased solid acid materials have attracted great attention due 
to their high chemical activity, high thermal stability, high specific surface area and low production costs. ${ }^{21-23}$ These sulfonated carbon-based materials can be prepared by sulfonating activated carbon in sulfuric acid or pyrolyzing organics to form carbon materials and treating with acid subsequently and these materials can process higher acid density after sulfonation. Pang and co-workers placed the activated carbon in concentrated sulfuric acid at $250{ }^{\circ} \mathrm{C}$ under $\mathrm{N}_{2}$ to form a sulfonated carbon solid acid. ${ }^{24}$ The sucrose was used as carbon source and added SBA-15 hard template to form mesoporous carbon, followed by sulfonation with $\mathrm{SO}_{3} / \mathrm{H}_{2} \mathrm{SO}_{4} \cdot{ }^{25}$ In our previous work, sulfonated carbon catalyst (SC-CCA), where the carbon source was from sucrose, was employed to catalyze xylose and corn stalk into furfural in GVL. ${ }^{26}$ Although solid acid catalysts largely decrease environmental pollution and equipment corrosion, the product yield is low and there are high reaction temperature and long residence time during the reaction process. Therefore, in order to improve furfural yield and enhance the reaction efficiency, graphene-based solid acid catalyst was employed to produce furfural from xylose and corn stalk in this work.

Graphene-based materials have attracted great attention in recent years due to its unique properties such as thermal conductivity, electrical, optical and catalytic properties. Sulfonated graphene has been applied in the hydrolysis of ethyl acetate,${ }^{27}$ the dehydration of fructose to $\mathrm{HMF},{ }^{28}$ and catalytic conversion of levulinic acid to GVL. ${ }^{29}$ In addition, different solvents have been used to convert xylose and corn stalk to furfural, and in order to increase the yield of furfural in a greener way, we need to choose an optimal solvent solution. Water, the inexpensive and eco-friendly solvent, has been used for furfural production. However, the yield of furfural was fairly low because of the degradation of furfural in water. ${ }^{30}$ GVL derived from biomass has been used for furfural production. Using GVL as a solvent will decrease the activation energy barrier of xylose dehydration and increase the rampart of furfural degradation, therefore, the dehydration rate of xylose will increase, in contrast, the degradation rate of furfural will decrease..$^{20,30}$ Zhang and co-workers dehydrated xylose to produce furfural in GVL by using $\mathrm{FeCl}_{3} \cdot 6 \mathrm{H}_{2} \mathrm{O}$ as catalyst with a $86.5 \%$ furfural yield at $170{ }^{\circ} \mathrm{C} .{ }^{31}$ Solid acid catalyst was used to dehydrate xylose and corn stalk into furfural by using GVL as solvent with a $78.5 \%$ furfural yield from xylose at $170{ }^{\circ} \mathrm{C} .{ }^{26} \mathrm{GVL}$ is a nontoxic and green solvent and the product furfural is easily separated from GVL by distillation. Therefore, GVL was used as the solvent to produce furfural in this study.

Diazonium of sulfanilic acid and sodium nitrite formed in situ has been used in this work to prepare sulfonated graphene ${ }^{32}$ and we contributed to the efficient furfural production from corn stalk and xylose. For the conversion of corn stalk, the furfural yield would exceed $100 \%$ if calculated by adopting the starting moles of xylan in corn stalk because of extra furfural production from glucan in corn stalk, consequently, combined moles of starting xylan and glucan in corn stalk were used to calculate furfural yield in this work. A 48\% furfural yield was obtained from corn stalk at in $50 \mathrm{~min}$, and what's more a furfural yield of $40 \%$ was obtained from corn stalk just in
$10 \mathrm{~min}$, which have been reported barely for efficient production of furfural at such less reaction time in previous articles. The catalyst was synthesized and characterized by a variety of equipment to confirm its structure. The reaction temperature, reaction time, various solvent and dosage of catalyst and substrate were investigated in the process of reaction of conversion xylose and corn stalk into furfural. In addition, the stability and reusability of SG were also investigated.

\section{Materials and methods}

\subsection{Materials}

D-Xylose (98\%), furfural (99\%), sulfanilic acid (AR, 99.5\%), sodium nitrite (AR, 99\%), 5-HMF (99\%) and $\gamma$-butyrolactone (AR, GBL) were purchased from Aladdin Industrial Inc. (Shanghai, China). Graphite powder (SP), hydrazine hydrate (AR, 85\%), sulfuric acid (AR, 95-98\%), hydrochloric acid (AR, 36-38\%), 1,4-dioxane (AR), dimethylsulfoxide (AR, DMSO), dimethylformamide (AR, DMF) and other reagents were purchased from Sinopharm Chemical Reagent Co. Ltd (Shanghai, China). $\gamma$-Valerolactone (95\%, GVL) was bought from Langfang Hawk Technology and Development. Co., Ltd (Langfang, Hebei, China). All reagents were directly used as received without further treatment. The corn stalk used in this study came from Mengcheng, Anhui, China. The corn stalk was washed with water and then dried in oven. The corn stalk was ground into particles to a size of 40 mesh and then further dried to constant weight.

\subsection{Graphite oxide (GO) preparation}

Graphite oxide was prepared by a slightly modified Hummer's method..$^{33}$ Graphite powder ( $3.0 \mathrm{~g}$ ) was added into a mixture of concentrated $12 \mathrm{~mL} \mathrm{H}_{2} \mathrm{SO}_{4}, 2.5 \mathrm{~g} \mathrm{P}_{2} \mathrm{O}_{5}$, and $2.5 \mathrm{~g} \mathrm{~K}_{2} \mathrm{~S}_{2} \mathrm{O}_{8}$. The solution was kept at $80{ }^{\circ} \mathrm{C}$ and agitated for $4.5 \mathrm{~h}$ by using an oilbath. The solution was then cooled down to the room temperature and diluted with $0.5 \mathrm{~L}$ double distilled water and left overnight. Finally, the product was washed with double distilled water several times to remove the residual acid. The product was dried at ambient temperature.

The pre-oxidized graphite powder $(1.0 \mathrm{~g})$ was put into a cold $\left(0{ }^{\circ} \mathrm{C}\right)$ concentrated $\mathrm{H}_{2} \mathrm{SO}_{4}(27.5 \mathrm{~mL})$ solution and stirred. $\mathrm{KMnO}_{4}(3.5 \mathrm{~g})$ was then added gradually under stirring while the temperature of the mixture was maintained below $20{ }^{\circ} \mathrm{C}$. Successively, the mixture was stirred at $35^{\circ} \mathrm{C}$ for $2 \mathrm{~h}$ and then carefully diluted with double distilled water $(115 \mathrm{~mL})$. This lead to the release of a large amount of heat and kept the temperature at $50{ }^{\circ} \mathrm{C}$. After adding all of the $58 \mathrm{~mL}$ double distilled water, the solution was stirred for $2 \mathrm{~h}$ and then additional water $(230 \mathrm{~mL}$ ) was added and stirred for a while. Then $5 \mathrm{~mL}$ of $30 \%$ $\mathrm{H}_{2} \mathrm{O}_{2}$ was put into mixture in drop, and the color of solution changed into brilliant yellow along with bubbling. The mixture was washed with $1: 10 \mathrm{HCl}$ aqueous solution $(500 \mathrm{~mL})$ three times by centrifugation at $4500 \mathrm{rpm}$ for $5 \mathrm{~min}$ to remove metal ions, and then washed with double distilled water until neutral and no chloride ion detected by $\mathrm{AgNO}_{3}$ aqueous solution. The product was collected by lyophilization. 


\subsection{Sulfonated graphene preparation}

Graphite oxide (500 mg) was added into $250 \mathrm{~mL}$ double distilled water and exfoliated to graphene oxide by ultrasonication of graphite oxide dispersion $\left(2 \mathrm{mg} \mathrm{mL} \mathrm{m}^{-1}\right)$. Then, a $5 \%$ sodium carbonate solution was added so as to make the $\mathrm{PH}$ of the mixture achieve 9-10. Finally, $10 \mathrm{~mL}$ 64\% hydrazine hydrate was put into the suspension and the solution was allowed to reflux for 24 hours at $95{ }^{\circ} \mathrm{C}$. The mixture was cooled to ambient temperature and filtered through Millipore membrane $(0.45 \mu \mathrm{m})$ and washed with double distilled water and methanol. The product, reduced graphene oxide (RGO), was freeze-dried and collected.

RGO (245 mg) was added into $40 \mathrm{~mL}$ water and allowed to sonicate for $1 \mathrm{~h}$. Then, $2.108 \mathrm{~g}$ sodium nitrite and $1.757 \mathrm{~g}$ sulfanilic acid were added into the resulting mixture, where the diazonium would be formed. The mixture was stirred for $24 \mathrm{~h}$ at room temperature to achieve sulfonated graphene. The solution was filtered through Millipore membrane and washed with $100 \mathrm{~mL} 1 \mathrm{M} \mathrm{HCl}$, double distilled water and $200 \mathrm{~mL}$ acetone repeatedly; this process has proved to be specifically efficient in the isolation of SG at high purity. ${ }^{34-36}$ The black power was acquired by lyophilization for $24 \mathrm{~h}$.

\subsection{Catalyst characterization}

The catalyst materials were characterized using SEM from an XL-30 ESEM instrument (FEI Company, USA) and TEM from a JEM-2100F instrument (JEOL, Japan). The sample was dispersed in the alcohol with the aid of ultrasound, and then dropped onto a copper grid until it became dried under warm light. FTIR spectra were recorded from samples using a Thermo Scientific Nicolet iS-50 instrument with a KBr disk over a range of 400-4000 $\mathrm{cm}^{-1}$. The XPS measurement was carried from an ESCALAB 250 instrument that employs monochromatic Al K $\alpha$ radiation $(1486.6 \mathrm{eV})$.

\subsection{Catalytic conversion of xylose}

The catalytic reaction took place in a $15 \mathrm{~mL}$ sealed thick-walled glass tube with $28 \mathrm{mg}$ of the catalyst, $60 \mathrm{mg}$ xylose and $10 \mathrm{~mL}$ solvent under magnetic stirring. The tube was heated at a specific temperature and sustained for different reserved times in an oil bath. After the reaction, the reactor was cooled to room temperature, and the reaction mixture was filtered, collected, and stored in a refrigerator for subsequent analysis.

\subsection{Catalytic conversion of corn stalk}

The compositional analysis had been summarized in previous articles by our research group. ${ }^{17}$ There are mainly $20.5 \%$ xylan, $31.6 \%$ glucan and $22.8 \%$ lignin in raw corn stalk and some other minor components such as glycan, extractive, ash etc. The catalytic reaction was performed in a $25 \mathrm{~mL}$ stainless-steel autoclave. In a typical process, $75 \mathrm{mg}$ corn stalk was dispersed $10 \mathrm{~mL}$ GVL and mixed with $35 \mathrm{mg}$ catalyst. The reactor was heated up to $190{ }^{\circ} \mathrm{C}$ for $50 \mathrm{~min}$ at $600 \mathrm{rpm}$. At the end of the reaction, the reactor was immediately cooled with cold water, and the reaction mixture was filtered, collected, and stored in refrigerator for subsequent analysis.
The samples were analyzed by high performance liquid chromatography (HPLC, LC-2010AHT, SHIMADZU) equipped with a C18 column (ZORBAX, Eclipse XDB-C18, Agilent) and an UV detector (SPD-10A, SHIMADZU) at $280 \mathrm{~nm}$. A mixture solution of methanol and water $(2 / 3 \mathrm{v} / \mathrm{v})$ was used as the mobile phase $\left(0.4 \mathrm{~mL} \mathrm{~min}^{-1}\right)$, and the column temperature was maintained at $30{ }^{\circ} \mathrm{C}$. Furfural and HMF yields for the various products have been calculated on a molar basis as follows:

furfural yield (from xylose) $=$ (moles of furfural produced $/$ moles of starting xylose) $\times 100 \%$

furfural yield (from corn stalk) $=$ (moles of furfural produced/ moles of starting xylan and glucan in corn stalk) $\times 100 \%$

furfural yield (from fructose) $=($ moles of furfural produced $/$ moles of starting fructose) $\times 100 \%$

furfural yield (from glucose) $=($ moles of furfural produced $/ \mathrm{moles}$ of starting glucose) $\times 100 \%$

furfural yield (from cellulose) $=$ (moles of furfural produced/ moles of starting cellulose) $\times 100 \%$

HMF yield $($ from corn stalk $)=($ moles of HMF produced $/$ moles of starting glucan in corn stalk) $\times 100 \%$

\section{Results and discussion}

\subsection{Characterization of catalyst}

SEM and TEM revealed the morphologies of RGO, SG and used SG (the 5th recycling SG) as shown in Fig. S1. $\dagger$ It can be seen from SEM and TEM images of the catalysts that RGO and SG exhibit a curled and layered structure. After fives reactions, the morphology of SG barely changed while the acid density decreased by elemental analysis as shown in Table 1. The thermal stability of SG was tested by using thermogravimetric analysis (TGA) with a heating rate of $10{ }^{\circ} \mathrm{C} \mathrm{min}{ }^{-1}$ under $\mathrm{N}_{2}$ atmosphere as shown in Fig. S2. $\dagger$ The mass losses of $15.06 \%$ below $130{ }^{\circ} \mathrm{C}$ could be attributed to volatiles' desorption, mainly moisture. The sample was then steady until $190{ }^{\circ} \mathrm{C}$ at which point the TGA spectrum for SG clearly showed a weight loss corresponding to the gradual disappearance of the grafted sulfonic acid groups. ${ }^{32}$

The FT-IR spectra of GO, RGO, and SG presented different functional groups on the graphene sheet as shown in Fig. S3. $\uparrow$ The pristine graphite oxide reveal the presence of $\mathrm{C}-$ $\mathrm{O}, \mathrm{C}-\mathrm{OH}, \mathrm{C}=\mathrm{O}$, carbonyl moieties stretching vibration at

Table 1 The elemental analysis of SG and used SG ${ }^{a}$ catalysts

\begin{tabular}{lllll}
\hline Entry & $\mathrm{N}(\%)$ & $\mathrm{C}(\%)$ & $\mathrm{S}(\%)$ & $\mathrm{SO}_{3} \mathrm{H}$ density $\left(\mathrm{mmol} \mathrm{g}^{-1}\right)$ \\
\hline SG & 1.42 & 51.50 & 6.565 & 2.05 \\
Used SG & 2.03 & 59.24 & 4.325 & 1.35
\end{tabular}

${ }^{a}$ The 5 th recycling SG catalyst. 
1060, 1230 (epoxy), 1384, 1630 and $1732 \mathrm{~cm}^{-1}$ (carboxylic acid and carbonyl moieties) respectively. ${ }^{37,38}$ After reduction with hydrazine hydrate, peaks at 1060, 1230, 1398, $1630 \mathrm{~cm}^{-1}$ almost disappeared while peak at $1570 \mathrm{~cm}^{-1}$ appeared indicating the dehydration and reduction of $\mathrm{O}-\mathrm{H}, \mathrm{C}-\mathrm{O}$, and $\mathrm{C}=\mathrm{O}$ and appearance of $\mathrm{N}-\mathrm{H} .{ }^{37}$ The sulfonation of RGO to SG peaks at $616,1002,1030,1121$, and $1175 \mathrm{~cm}^{-1}$ confirmed the existence of $\mathrm{SO}_{3} \mathrm{H}$ with catalyst ${ }^{17}$ and after five reaction runs with $\mathrm{SG}$ catalyst, the peaks of $\mathrm{SO}_{3} \mathrm{H}$ decayed due to $\mathrm{SO}_{3} \mathrm{H}$ falling from catalyst. The sulfur element was uniformly dispersed on the surface of SG revealed in EDS mapping (Fig. S4†).

X-ray photoelectron spectroscopy (XPS) was used to carry out the surface characterization and trace the evolution of the structural properties of the materials as shown in Fig. 1. The surface oxygen functional groups and distribution of GO were verified by deconvoluting the $\mathrm{C}$ 1s peak into its relative components (Fig. 1A). The $\mathrm{C}-\mathrm{C}$ bond at $\sim 284.6 \mathrm{eV}$ and $\mathrm{C}-\mathrm{O}$ (including epoxide and hydroxyl) bond at $\sim 286.8 \mathrm{eV}$ formed two main peaks in GO respectively. The peaks at $\sim 287.6$ and
$288.9 \mathrm{eV}$ are ascribed to $\mathrm{C}=\mathrm{O}$ and $\mathrm{O}-\mathrm{C}=\mathrm{O}$ bonds, respectively. After reduction by hydrazine hydrate, the RGO exhibited similar valence states for the carbon element to the GO, but the peak intensity of some oxygen-containing groups (such as $\mathrm{C}-\mathrm{O}, \mathrm{C}=$ O) are much lower than those in GO (Fig. 1B), meaning that a large amount of oxygen functional groups were shed during the reduction process. In addition to those oxygen-containing, the $\mathrm{C}-\mathrm{N}$ peak at $\sim 285.8 \mathrm{eV}$ appeared in RGO due to the reduction of hydrazine hydrate. ${ }^{39} \mathrm{SG}$ has the same carbon valence state as RGO after sulfonation with sodium nitrite and sulfanilic acid in situ (Fig. 1C). The two peaks at 232.1 and $168.1 \mathrm{eV}$ corresponding to $S 2 \mathrm{~s}$ and $\mathrm{S} 2 \mathrm{p}$, respectively, suggest that the sulfonic acid group successfully grafts onto the surface of material (Fig. 1E). The S 2p binding energy (168.1 eV), which is slightly lower than the anticipated value of sulfonic acid (168.8 eV) can be explained by electron transfers from graphene to sulfonic acid groups (Fig. 1D), and the small peak at $\sim 400 \mathrm{eV}$ is ascribed to $\mathrm{N}$ 1s due to the use of hydrazine hydrate to reduce graphene oxide to graphene. This view can be confirmed by the small peaks in the XPS spectrum of RGO. ${ }^{32}$
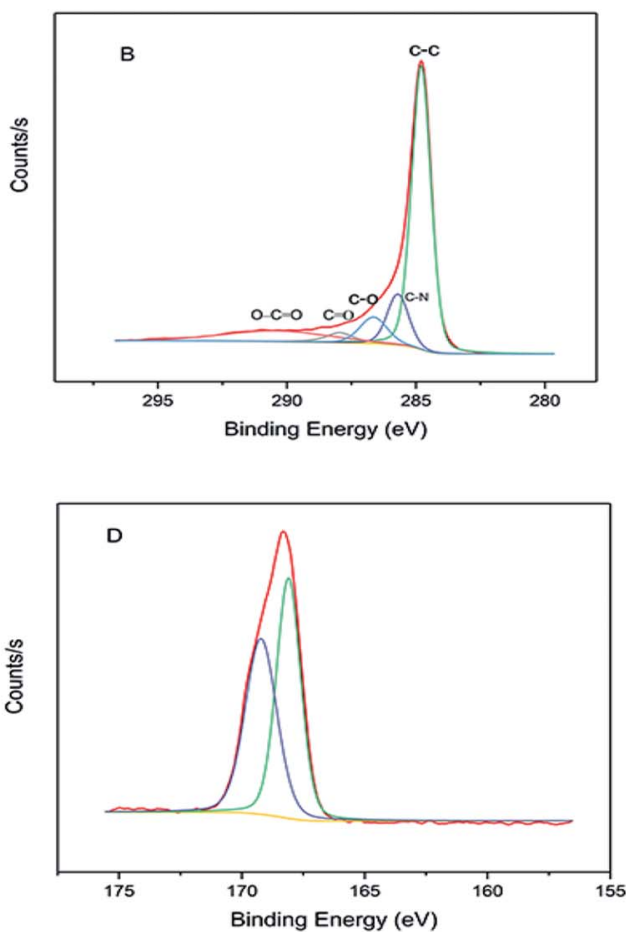

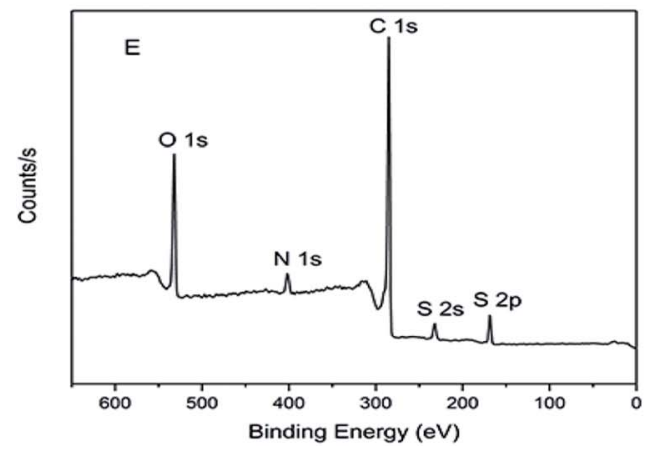

Fig. 1 High resolution XPS spectrum of C 1s in GO (A), RGO (B) and SG (C). (D) High resolution of S 2p spectrum of SG. (E) Survey scan spectra of SG.

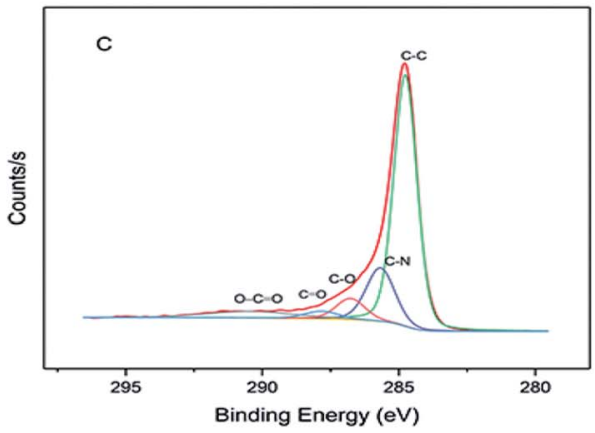




\subsection{Effects of temperature and time on the yield of furfural}

The effects of reaction time and temperature on the production of furfural from corn stalk and xylose were studied, and the result was shown in Fig. 2 . The study found that temperature and time had a positive influence on the furfural yield. As shown in Fig. 2A, when the running temperature of xylose was increased from 130 to $140{ }^{\circ} \mathrm{C}$, the yield of furfural increased sharply. When the temperature was $150{ }^{\circ} \mathrm{C}$, the yield of furfural reached a maximum of $96 \%$ in 40 minutes. The furfural yield at $140{ }^{\circ} \mathrm{C}(92.3 \%)$ was slightly lower than that at $150{ }^{\circ} \mathrm{C}$. Therefore, considering energy conservation, xylose conversion was carried out at $140{ }^{\circ} \mathrm{C}$ for other experiments, the result of which was impressive in terms of the conversion to xylose into furfural in such low temperature compared to using other solid acids. As the reaction temperature continued to rise, the yield of furfural slowly decreased, because an increase in temperature causes the polymerization of the small furfural molecule. ${ }^{26,40}$ For corn stalk, the yield of furfural increased slowly with increasing temperature (130-190 $\left.{ }^{\circ} \mathrm{C}\right)$, which might be due to the initial hydrolysis of cellulose and hemicellulose into hexoses and pentoses, followed by the dehydration of the latter to form furfural. The yield of furfural reached
$48 \%$ at $190{ }^{\circ} \mathrm{C}$ in 50 minutes. The variation of furfural yield with time was similar to that of temperature as shown in Fig. 2B. When residence time was excessively increased, the yield of furfural would decrease due to condensation and degradation of products. However, it is worth noting that a yield of $40 \%$ was achieved in only $10 \mathrm{~min}$ at $190{ }^{\circ} \mathrm{C}$ for conversion of corn stalk into furfural. The effects of temperature and time on 5-HMF production from corn stalk are also investigated (Fig. S5 $\dagger$ ) and a $19 \%$ 5-HMF yield was gained at $180{ }^{\circ} \mathrm{C}$ in $50 \mathrm{~min}$ and more details are summarized in the ESI. $\dagger$ A desirable furfural yield was achieved in such a short reaction time, which indicates that the sulfonated graphene catalyst exhibits superior catalytic activity and high selectivity and well dispersed in solvent.

Controlled experiments were conducted and the results were shown in Table 2. There was no furfural production in the absence of catalyst. This result is the same as using RGO catalyst, which further illustrates the importance of acidity in the production of furfural from corn stalk. The effects of other catalysts in previous articles on furfural yield were also listed as shown in Table 2. A 43.9\% furfural yield was obtained when using SG catalyst in only $20 \mathrm{~min}$ and the furfural production
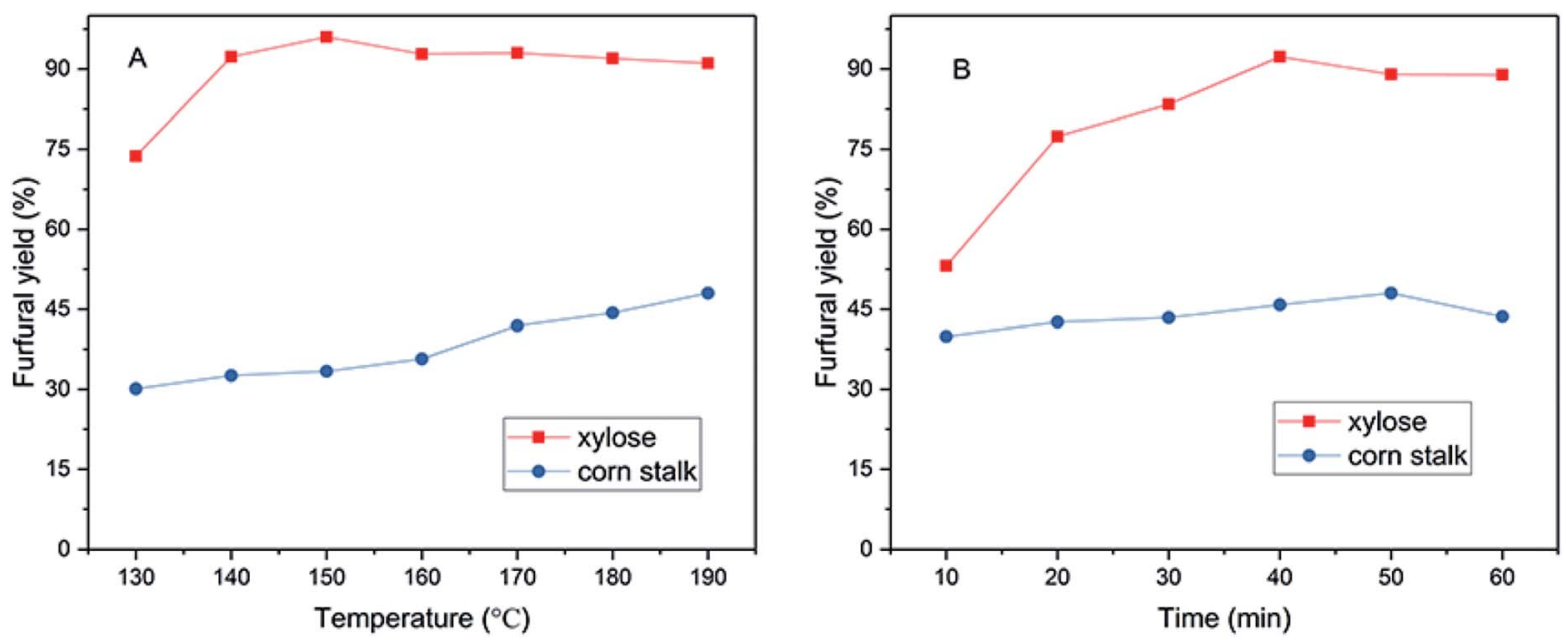

Fig. 2 Effects of temperature (A) and time (B) on furfural production from xylose and corn stalk. Reaction conditions: for xylose: 28 mg catalyst, $60 \mathrm{mg}$ xylose, $10 \mathrm{~mL} \mathrm{GVL}$, for corn stalk: $35 \mathrm{mg}$ catalyst, $75 \mathrm{mg}$ corn stalk, $10 \mathrm{~mL}$ GVL. (A) Reaction time: $40 \mathrm{~min}$ and $50 \mathrm{~min}$ for xylose and corn stalk. (B) Reaction temperature: $140{ }^{\circ} \mathrm{C}$ and $190^{\circ} \mathrm{C}$ for xylose and corn stalk.

Table 2 Furfural production from biomass using diverse catalyst ${ }^{a}$

\begin{tabular}{lllllll}
\hline Catalyst & Catalyst mass $(\mathrm{mg})$ & Reaction conditions & Substrate & Furfural yield $(\%)$ & $\begin{array}{l}\text { Furfural production relative rate } \\
\left(\mathrm{min}^{-1} \mathrm{mg}^{-1}\right)\end{array}$ \\
\hline No catalyst & 0 & $190^{\circ} \mathrm{C}, 20 \mathrm{~min}$ & Corn stalk & Trace & 0 & This work \\
RGO & 40 & $190{ }^{\circ} \mathrm{C}, 20 \mathrm{~min}$ & Corn stalk & Trace & 0 & This work \\
SG & 40 & $190{ }^{\circ} \mathrm{C}, 20 \mathrm{~min}$ & Corn stalk & $43.9 / 100.3^{b}$ & 0.125 & This work \\
SC-CaCt-700 & 45 & $200^{\circ} \mathrm{C}, 100 \mathrm{~min}$ & Corn stalk & $93^{b}$ & 0.021 & 17 \\
SC-CCA & 300 & $200{ }^{\circ} \mathrm{C}, 100 \mathrm{~min}$ & Corn stalk & $60.6^{b}$ & 0.002 & 26 \\
S-RFC & 600 & $200^{\circ} \mathrm{C}, 100 \mathrm{~min}$ & Corn stalk & $68.6^{b}$ & 0.001 & 41 \\
SPTPA & 30 & $175{ }^{\circ} \mathrm{C}, 30 \mathrm{~min}$ & Corn cob & $73.9^{b}$ & 0.082 & 42 \\
FeCl $_{3}$ & 9.6 & $185{ }^{\circ} \mathrm{C}, 100 \mathrm{~min}$ & Corn cob & $79.6^{b}$ & 0.083 & 31
\end{tabular}

${ }^{a}$ Reaction solvent: GVL. ${ }^{b}$ Furfural yield was calculated only from xylan part of corn stalk and corn cob. ${ }^{c}$ Furfural production relative rate $=$ furfural yield/(reaction time $\times$ catalyst mass). 


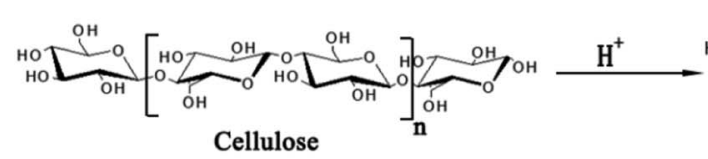

(O)
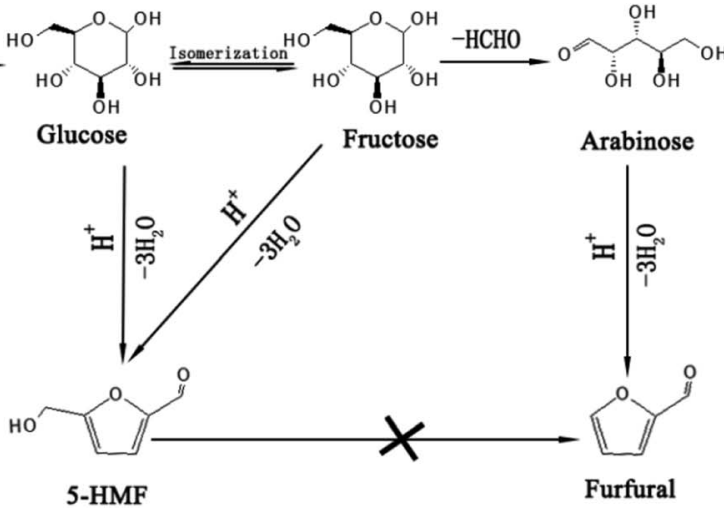

Fig. 3 Plausible reaction pathway for the transformation of hexoses into furfural.

relative rate was up to $0.125 \mathrm{~min}^{-1} \mathrm{mg}^{-1}$, which can prove that SG exhibits high performance in the process of catalytic conversion of corn stalk into furfural compared to other acidic catalysts, such as SC-CaCt-700, SC-CCA, S-RFC, SPTPA, and $\mathrm{FeCl}_{3}$.

The mechanism for the conversion of glucose and fructose into furfural has been studied in recent years and it has been found that hexoses could also be converted to furfural under an acid system, ${ }^{\mathbf{4 3 , 4 4}}$ which could be explained as shown in Fig. 3. Glucose was converted to fructose through isomerization by $\mathrm{N}$-doped graphene on Lewis acid sites ${ }^{45}$ and then fructose was converted to arabinose by decarbonylation. Finally, furfural was obtained by the dehydration of arabinose. In order to confirm if the hexoses and cellulose could be converted to furfural, some additional experiments were carried out, and in addition, the convertibility of the by-product, 5-HMF, to furfural (see Table 3). Cellulose, glucose and fructose can all be converted to furfural under the same reaction system. Therefore, the cellulose fraction of corn stalk should also be involved when calculating the yield of furfural. It was reported that 5-HMF was also converted to furfural by decarbonylation; ${ }^{46}$ however, there was no furfural found in our reaction system by using 5 -HMF as substrate. This shows that different reaction systems give diverse possible pathways for the transformation of hexoses into furfural and the mechanism needs to be further explored.

\subsection{Effects of catalyst and substrate loading on the yield of furfural}

The effects of catalyst dosage and substrate loading on furfural yield were studied in this work (Fig. 4). The amount of xylose (60

Table 3 Effects of diverse substrate on furfural production by using sulfonated graphene catalyst ${ }^{a}$

\begin{tabular}{llll}
\hline Substrate & Solvent & Reaction conditions & $\begin{array}{l}\text { Furfural yield } \\
(\%)\end{array}$ \\
\hline Fructose & GVL & $190{ }^{\circ} \mathrm{C}, 50 \mathrm{~min}$ & 17.8 \\
Glucose & GVL & $190^{\circ} \mathrm{C}, 50 \mathrm{~min}$ & 22.4 \\
Cellulose & GVL & $190{ }^{\circ} \mathrm{C}, 50 \mathrm{~min}$ & 23.2 \\
Fructose & GVL & $170{ }^{\circ} \mathrm{C}, 40 \mathrm{~min}$ & 18.3 \\
Glucose & GVL & $170{ }^{\circ} \mathrm{C}, 40 \mathrm{~min}$ & 23.3 \\
Cellulose & GVL & $170{ }^{\circ} \mathrm{C}, 40 \mathrm{~min}$ & 25.5 \\
HMF & GVL & $170{ }^{\circ} \mathrm{C}, 40 \mathrm{~min}$ & Trace
\end{tabular}

${ }^{a} 35 \mathrm{mg}$ catalyst, $75 \mathrm{mg}$ substrate, $10 \mathrm{~mL}$ GVL. $\mathrm{mg}$ ) and corn stalk (75 mg) was each kept constant, which was used to explore the changes of yields by changing the amount of catalyst as shown in Fig. 4A. Furfural yield went up gradually with an increase in the catalyst dosage; $92.3 \%$ and $43.9 \%$ furfural yields were obtained from xylose in $40 \mathrm{~min}$ and corn stalk in $20 \mathrm{~min}$, where the mass ratios of catalyst to substrate were $7: 15$ and $4: 6$, respectively. It is noteworthy that since there was almost no difference in furfural yield of conversion corn stalk when using a mass ratio of $7: 15$ (SG/corn stalk) compared to ratio of $4: 6$, therefore, a mass ratio of $7: 15$ was adopted to execute corn stalk conversion in other experiments in this work. Furfural yield decreased slowly or remained constant (Fig. 4A), when the catalyst loading continued to increase, which is because side reactions like condensation, polymerization and resinification occurred under excessive acidic medium (provided by SG). ${ }^{20,40}$ The 5-HMF yield reached $8 \%$ when using a $2: 6$ mass ratio at $190^{\circ} \mathrm{C}$ in $20 \mathrm{~min}$ and the yield also decreased as the catalyst loading further increased as shown in Fig. S5C. $\dagger$

Similarly, catalyst dose was also fixed to inspect the change in furfural yield by changing substrate loading. As shown in Fig. 4B (substrate loading: mass ratio of corn stalk to catalyst), furfural yield gradually decreased as the substrate loading increased. This might be ascribed to the occurrence of condensation and polymerization reactions among products, intermediates and reactants, as higher substrate dose increases the probability of molecular collision in reactions. ${ }^{47,48}$ The highest furfural yield was obtained from xylose and corn stalk at the substrate loading of 2.14 respectively. It was worth noting that a $71.9 \%$ furfural yield was obtained at a substrate loading of 10.7 within 40 minutes at $140{ }^{\circ} \mathrm{C}$, which was a high value for furfural production under such a substrate loading. For the corn stalk, a 31.6\% furfural yield was obtained with a substrate loading of 4.28 , which was a relatively higher value for conversion of corn stalk into furfural. The effect of substrate loading on 5 -HMF production was similar to that on furfural production. A 15.1\% 5-HMF yield was obtained with a 2.14 substrate loading and the yield declined as substrate loading increased (Fig. S5D $\dagger$ ). More humins were formed as the corn stalk dosage increased and deposited on the surface of catalyst, which caused catalyst deactivation and further hindered furfural production. 

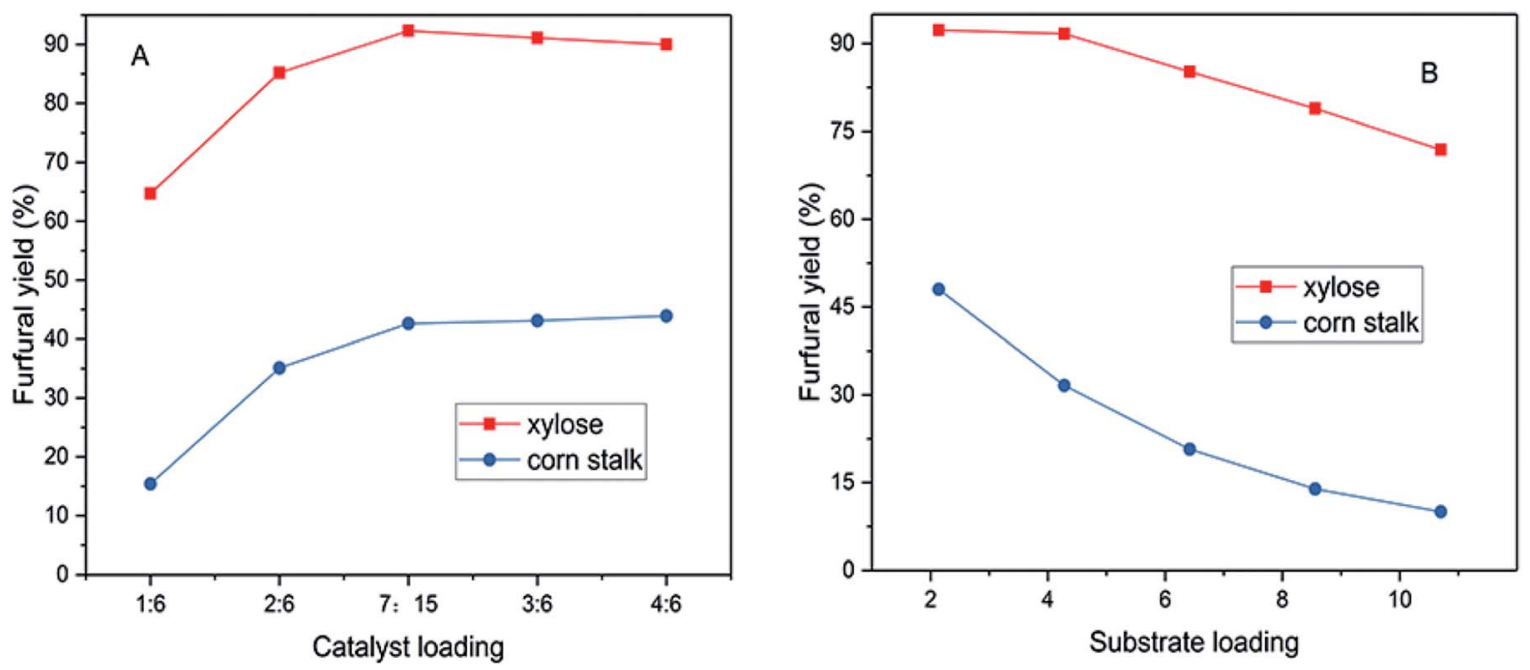

Fig. 4 Effects of catalyst loading (A) and substrate dose (B) on furfural production from xylose and corn stalk. Reaction conditions: $140{ }^{\circ} \mathrm{C}$, $40 \mathrm{~min}, 60 \mathrm{mg}$ xylose, $10 \mathrm{~mL} \mathrm{GVL}$ for xylose and $190^{\circ} \mathrm{C}, 20 \mathrm{~min}, 75 \mathrm{mg}$ corn stalk, $10 \mathrm{~mL} \mathrm{GVL}$ for corn stalk in (A). $140^{\circ} \mathrm{C}, 40 \mathrm{~min}, 28 \mathrm{mg}$ catalyst, $10 \mathrm{~mL}$ GVL for xylose and $190^{\circ} \mathrm{C}, 50 \mathrm{~min}, 35 \mathrm{mg}$ catalyst, $10 \mathrm{~mL} \mathrm{GVL}$ for corn stalk in (B). Catalyst loading = mass ratio of catalyst to xylose or corn stalk; substrate loading $=$ mass ratio of xylose or corn stalk to catalyst.

\subsection{Effects of various solvents on furfural production}

While the use of catalyst in the production of furfural from xylose and corn stalk is very crucial, the solvents system also plays a very vital role in the reaction process. Solvents will not only affect the product species, but also affect the reaction kinetics to change the yield of furfural by changing the stability of acidic protons relative to the protonated transition state. ${ }^{30,49}$

Under the same reaction conditions, water and different organic solvents were applied as reaction solvents, and the results are shown in Fig. 5. When using GVL as solvent, the highest furfural yields were achieved from xylose and corn stalk in these solvents involved in my experiments, respectively. GBL gave a relatively higher yield close to the result acquired from GVL, while 1,4-dioxane gave a medium yield. A extremely low yield was obtained when using DMSO, DMF and water as solvents and there was no 5-HMF formed when DMF and 1,4-dioxane were used as solvents (Fig. S5E $\dagger$ ). GVL is a promising solvent, which not only promotes the production of furfural, but also benefits other reactions such as dipropylene glycol's dehydration to

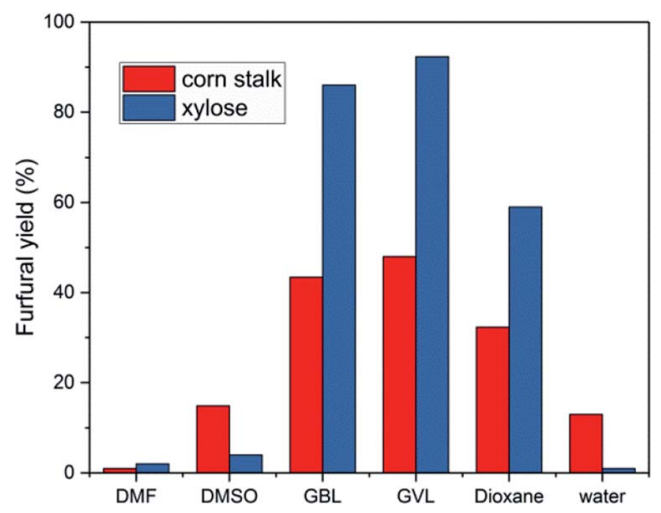

Fig. 5 Furfural production from xylose $\left(140{ }^{\circ} \mathrm{C}, 40 \mathrm{~min}, 60 \mathrm{mg}\right.$ xylose, $28 \mathrm{mg}$ catalyst) and corn stalk $\left(190^{\circ} \mathrm{C}, 50 \mathrm{~min}, 75 \mathrm{mg}\right.$ corn stalk, $35 \mathrm{mg}$ catalyst) in various solvents. propanol, cellulose pyrolysis to glucose. ${ }^{30}$ Although GVL favors the production of furfural, water, as a solvent, is greener, cheaper and abundant in the world. Therefore, experiments were conducted at 50,100,150,200, 250 minutes at $190{ }^{\circ} \mathrm{C}$ to observe the change in furfural yield from corn stalk in the aqueous phase (Fig. 6), and at the same time, a low 5-HMF yield was received. When the time was extended, furfural yield reached a maximum of $16.5 \%$ at $150 \mathrm{~min}$ and then began to slowly decrease. The yield of furfural obtained in water was much lower than that in GVL due to the stronger polarity of water which caused polymerization between furans. ${ }^{50}$ Although low yields of furfural and 5-HMF were obtained from water, water is a very important solvent for sustainable development from an industrial perspective. Therefore, the problem of low yield of furfural needs to be further looked into and solved by researchers.

\subsection{Catalyst reusability}

Reusability and solvent-stability of a catalyst are very significant factors for industry to assess the sustainability and profitability

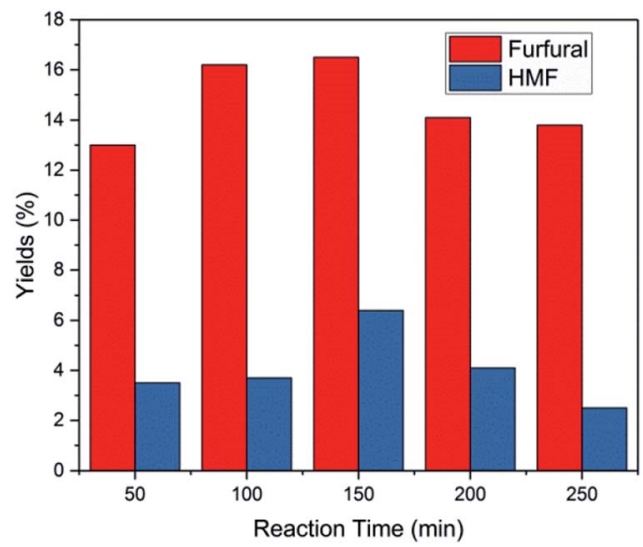

Fig. 6 Conversion of corn stalk in pure water $(10 \mathrm{~mL})$ with $75 \mathrm{mg}$ corn stalk and $35 \mathrm{mg}$ catalyst at $190^{\circ} \mathrm{C}$. 
of a process plant. To test the stability of the SG catalyst, five consecutive, recycling experimental runs were conducted and the results are shown in Table 4. Typically, $28 \mathrm{mg}$ SG and $60 \mathrm{mg}$ xylose were added into thick-walled glass and then $10 \mathrm{~mL}$ GVL was added as solvent with magnetic stirring (Entry 1). The reaction temperature was held at $140{ }^{\circ} \mathrm{C}$ by oil bath heating. At the end of reaction, the mixture was separated through a Millipore membrane. The product was collected and determined by HPLC and SG catalyst was washed with water and acetone repeatedly. The recycled SG was dried and used for next cycle.

The results in the Table 4 showed that the yield of furfural gradually decreased during five runs. After the fifth run, the yield of furfural reached $70 \%$, indicating strong acid density and desirable solvent-stability of SG. FT-IR and elemental analysis tests on the 5th recycling catalyst were carried out to investigate the reasons for the decrease in furfural yield. The acid density decreased and the FT-IR signal intensities of sulfonic acid group weakened, thus slight $\mathrm{SO}_{3} \mathrm{H}$ was leached during the five runs, which was the reason for the decrease of furfural yield.

In addition, the SG reusability for conversion of corn stalk was also studied. As we know, the reusability of catalysts is poor for the conversion of corn stalk, because of more humins formed, which will deposit on catalysts. ${ }^{17}$ On the other hand, the catalysts are hardly separated from the corn stalk residues after reaction, thus, the catalyst and residues were collected together after each run and then washed with water, acetone and GVL repeatedly, which was directly used as catalyst for the next run. The results are shown in Table 4 . First, $35 \mathrm{mg}$ catalyst and $75 \mathrm{mg}$ corn stalk were used in a stainless-steel autoclave at $190{ }^{\circ} \mathrm{C}$ for $50 \mathrm{~min}$ in the first set of cycles (Entry 2). The first run gave a yield of $46 \%$; however, fairly low yields of $\sim 10 \%$ were obtained from second run to fifth run. Then the second set of cyclic tests was performed by using $100 \mathrm{mg}$ catalyst and $50 \mathrm{mg}$ corn stalk at $190{ }^{\circ} \mathrm{C}$ for $50 \mathrm{~min}$. The first run gave a $31.3 \%$ yield, $25 \%$ yield at 2 nd run and the yields were maintained at around $15 \%$ for other runs as shown in Entry 3 . Unlike the second set of cycles, the reaction time of corn stalk conversion was kept at $15 \mathrm{~min}$ in the third set of cycles. The yields of furfural decreased from $39.6 \%$ to $12.1 \%$ slowly in the five runs as shown in Entry 4 . These results indicated that the yield of furfural decreased sharply in the 2 nd run when prolonging reaction time. More

Table 4 Reusability investigated of sulfonated graphene ${ }^{a}$

\begin{tabular}{llllll}
\hline & \multicolumn{6}{l}{ Furfural yield } & & \\
\cline { 2 - 6 } Entry & Run 1 & Run 2 & Run 3 & Run 4 & Run 5 \\
\hline $1^{b}$ & $92.3 \%$ & $84.2 \%$ & $80 \%$ & $79.3 \%$ & $70 \%$ \\
$2^{c}$ & $46 \%$ & $9.5 \%$ & $8.1 \%$ & $5.3 \%$ & $10.5 \%$ \\
$3^{d}$ & $31.3 \%$ & $25 \%$ & $14.2 \%$ & $13.7 \%$ & $16.9 \%$ \\
$4^{e}$ & $39.6 \%$ & $26.3 \%$ & $19.7 \%$ & $13.7 \%$ & $12.1 \%$
\end{tabular}

${ }^{a}$ Solvent: $10 \mathrm{~mL}$ GVL. ${ }^{b} 60 \mathrm{mg}$ xylose and $28 \mathrm{mg}$ SG, reaction temperature: $140{ }^{\circ} \mathrm{C}$, residence time: $40 \mathrm{~min} .{ }^{c} 75 \mathrm{mg}$ corn stalk and $35 \mathrm{mg}$ SG, reaction temperature: $190{ }^{\circ} \mathrm{C}$, residence time: $50 \mathrm{~min}$. ${ }^{d} 50 \mathrm{mg}$ corn stalk and $100 \mathrm{mg}$ SG, reaction temperature: $190{ }^{\circ} \mathrm{C}$, residence time: $50 \mathrm{~min} .{ }^{e} 50 \mathrm{mg}$ corn stalk and $100 \mathrm{mg} \mathrm{SG}$, reaction temperature: $190^{\circ} \mathrm{C}$, residence time: $15 \mathrm{~min}$. humins were generated due to the long reaction time, which deposited on the catalyst, leading to a decrease in catalytic activity. Therefore, it is necessary to cut down the reaction time to enhance catalyst reusability. In addition, the loss of sulfonic acid groups from SG, which causes a decrease in the hydrolysis capacity of the cellulose and hemicellulose fractions of corn stalk, would further affect the yield of furfural. Hence, the accumulated corn stalk residues, the decrease in acid density and humins deposition on the SG, responsible for catalyst deactivation, are the main causes of low the furfural production from corn stalk.

\section{Conclusions}

Sulfonated graphene was successfully prepared and high catalytic performance and acid density were observed during conversion of corn stalk and xylose into furfural. A $48 \%$ furfural yield from corn stalk was obtained, and more importantly, $40 \%$ yield obtained just in $10 \mathrm{~min}$ when a 2.14 mass ratio (corn/SG) was used. A 96\% furfural yield from xylose was obtained at $150{ }^{\circ} \mathrm{C}$, what's more, a furfural yield of $71.9 \%$ was achieved when using a xylose/SG mass ratio of 10.7 at $140{ }^{\circ} \mathrm{C}$. In addition, GVL, GBL and 1,4-dioxane also gave good performances in furfural production. Therefore, SG catalyst is a promising material for the production of furfural.

\section{Conflicts of interest}

There are no conflicts to declare.

\section{Acknowledgements}

This work is financially supported by the National Natural Science Foundation of China (51536009 and 51576199), the Natural Science Foundation of Guangdong Province (2017A030308010) and the Local Innovative and Research Teams Project of Guangdong Pearl River Talents Program (2017BT01N092).

\section{References}

1 Y. Liao, Q. Liu, T. Wang, J. Long, L. Ma and Q. Zhang, Green Chem., 2014, 16, 3305-3312.

2 J. J. Bozell and G. R. Petersen, Green Chem., 2010, 12, 539554.

3 W. Gong, C. Chen, Y. Zhang, H. Zhou, H. Wang, H. Zhang, Y. Zhang, G. Wang and H. Zhao, ACS Sustainable Chem. Eng., 2017, 5, 2172-2180.

4 J. J. Musci, A. B. Merlo and M. L. Casella, Catal. Today, 2017, 296, 43-50.

5 M. J. Taylor, L. J. Durndell, M. A. Isaacs, C. M. A. Parlett, K. Wilson, A. F. Lee and G. Kyriakou, Appl. Catal., B, 2016, 180, 580-585.

6 L. Liu, H. Lou and M. Chen, Int. J. Hydrogen Energy, 2016, 41, 14721-14731.

7 N. Merat, C. Godawa and A. Gaset, J. Chem. Technol. Biotechnol., 1990, 48, 145-159. 
8 L. Bui, H. Luo, W. R. Gunther and Y. Román-Leshkov, Angew. Chem., Int. Ed., 2013, 52, 8022-8025.

9 S. Zhu, Y. Xue, J. Guo, Y. Cen, J. Wang and W. Fan, ACS Catal., 2016, 6, 2035-2042.

10 H.-Y. Zheng, Y.-L. Zhu, B.-T. Teng, Z.-Q. Bai, C.-H. Zhang, H.-W. Xiang and Y.-W. Li, J. Mol. Catal. A: Chem., 2006, 246, 18-23.

11 H. Mehdi, V. Fábos, R. Tuba, A. Bodor, L. T. Mika and I. T. Horváth, Top. Catal., 2008, 48, 49-54.

12 H. J. Brownlee and C. S. Miner, Ind. Eng. Chem., 1948, 40, 201-204.

13 O. Yemis and G. Mazza, Bioresour. Technol., 2011, 102, 73717378.

14 T. vom Stein, P. M. Grande, W. Leitner and P. D. de Maria, ChemSusChem, 2011, 4, 1592-1594.

15 Z. Zhang and Z. K. Zhao, Bioresour. Technol., 2010, 101, 11111114.

16 Y. Yang, C. W. Hu and M. M. Abu-Omar, ChemSusChem, 2012, 5, 405-410.

17 W. Li, Y. Zhu, Y. Lu, Q. Liu, S. Guan, H. M. Chang, H. Jameel and L. Ma, Bioresour. Technol., 2017, 245, 258-265.

18 X. Shi, Y. Wu, P. Li, H. Yi, M. Yang and G. Wang, Carbohydr. Res., 2011, 346, 480-487.

19 A. Dias, M. Pillinger and A. Valente, J. Catal., 2005, 229, 414423.

20 E. I. Gurbuz, J. M. Gallo, D. M. Alonso, S. G. Wettstein, W. Y. Lim and J. A. Dumesic, Angew. Chem., Int. Ed., 2013, 52, 1270-1274.

21 M. Toda, A. Takagaki, M. Okamura, J. N. Kondo, S. Hayashi, K. Domen and M. Hara, Nature, 2005, 438, 178.

22 J. Wang, W. Xu, J. Ren, X. Liu, G. Lu and Y. Wang, Green Chem., 2011, 13, 2678-2681.

23 B. Zhang, J. Ren, X. Liu, Y. Guo, Y. Guo, G. Lu and Y. Wang, Catal. Commun., 2010, 11, 629-632.

24 J. Pang, A. Wang, M. Zheng and T. Zhang, Chem. Commun., 2010, 46, 6935-6937.

25 R. Xing, Y. Liu, Y. Wang, L. Chen, H. Wu, Y. Jiang, M. He and P. Wu, Microporous Mesoporous Mater., 2007, 105, 41-48.

26 T. Zhang, W. Li, Z. Xu, Q. Liu, Q. Ma, H. Jameel, H. M. Chang and L. Ma, Bioresour. Technol., 2016, 209, 108-114.

27 J. Ji, G. Zhang, H. Chen, S. Wang, G. Zhang, F. Zhang and X. Fan, Chem. Sci., 2011, 2, 484-487.

28 Q. Hou, W. Li, M. Ju, L. Liu, Y. Chen and Q. Yang, RSC Adv., 2016, 6, 104016-104024.

29 Y. Wang, Z. Rong, Y. Wang, T. Wang, Q. Du, Y. Wang and J. Qu, ACS Sustainable Chem. Eng., 2016, 5, 1538-1548.
30 M. A. Mellmer, C. Sener, J. M. Gallo, J. S. Luterbacher, D. M. Alonso and J. A. Dumesic, Angew. Chem., Int. Ed., 2014, 53, 11872-11875.

31 L. Zhang, H. Yu, P. Wang and Y. Li, Bioresour. Technol., 2014, 151, 355-360.

32 N. Oger, Y. F. Lin, C. Labrugère, E. Le Grognec, F. Rataboul and F.-X. Felpin, Carbon, 2016, 96, 342-350.

33 Y. Zheng, Y. Jiao, L. Ge, M. Jaroniec and S. Z. Qiao, Angew. Chem., Int. Ed., 2013, 52, 3110-3116.

34 F. Kim, J. Luo, R. Cruz-Silva, L. J. Cote, K. Sohn and J. Huang, Adv. Funct. Mater., 2010, 20, 2867-2873.

35 D. Krishnan, F. Kim, J. Luo, R. Cruz-Silva, L. J. Cote, H. D. Jang and J. Huang, Nano Today, 2012, 7, 137-152.

36 J. Y. Luo, J. Kim and J. X. Huang, Acc. Chem. Res., 2013, 46, 2225-2234.

37 L. Lai, L. Chen, D. Zhan, L. Sun, J. Liu, S. H. Lim, C. K. Poh, Z. Shen and J. Lin, Carbon, 2011, 49, 3250-3257.

38 S. Sadhukhan, T. K. Ghosh, D. Rana, I. Roy, A. Bhattacharyya, G. Sarkar, M. Chakraborty and D. Chattopadhyay, Mater. Res. Bull., 2016, 79, 41-51.

39 P. Wu, Y. Qian, P. Du, H. Zhang and C. Cai, J. Mater. Chem., 2012, 22, 6402-6412.

40 R. F. Perez and M. A. Fraga, Green Chem., 2014, 16, 39423950.

41 Y. Zhu, W. Li, Y. Lu, T. Zhang, H. Jameel, H.-m. Chang and L. Ma, RSC Adv., 2017, 7, 29916-29924.

42 L. Zhang, G. Xi, J. Zhang, H. Yu and X. Wang, Bioresour. Technol., 2017, 224, 656-661.

43 J. Cui, J. Tan, T. Deng, X. Cui, Y. Zhu and Y. Li, Green Chem., 2016, 18, 1619-1624.

44 L. Zhang, G. Xi, Z. Chen, D. Jiang, H. Yu and X. Wang, Chem. Eng. J., 2017, 307, 868-876.

45 C. Rizescu, I. Podolean, J. Albero, V. I. Parvulescu, S. M. Coman, C. Bucur, M. Puche and H. Garcia, Green Chem., 2017, 19, 1999-2005.

46 L. Faba, B. T. Kusema, E. V. Murzina, A. Tokarev, N. Kumar, A. Smeds, E. Díaz, S. Ordóñez, P. Mäki-Arvela, S. Willför, T. Salmi and D. Y. Murzin, Microporous Mesoporous Mater., 2014, 189, 189-199.

47 B. Danon, G. Marcotullio and W. de Jong, Green Chem., 2014, 16, 39-54.

48 L. Zhang, H. Yu, P. Wang, H. Dong and X. Peng, Bioresour. Technol., 2013, 130, 110-116.

49 X. Hu, R. J. M. Westerhof, D. Dong, L. Wu and C.-Z. Li, ACS Sustainable Chem. Eng., 2014, 2, 2562-2575.

50 G. M. González Maldonado, R. S. Assary, J. Dumesic and L. A. Curtiss, Energy Environ. Sci., 2012, 5, 6981-6989. 